\title{
Methylglyoxal: A newly detected and potentially harmful metabolite in the blood of ketotic dairy cows
}

\author{
Chao Li, ${ }^{*} \dagger$ Shaohua Dai, ${ }^{*}$ Jiangyi Lu, ${ }^{*}$ Baoyu Zhao, ${ }^{*}$ Jiangang Wang,‡ Panpan Li, ${ }^{*}$ Zhaozhen Wu, ${ }^{*}$ \\ Yingying Mu, ${ }^{*}$ Cuixia Feng, ${ }^{*}$ and Qiang Dong*1 \\ ${ }^{*}$ College of Veterinary Medicine, Northwest A\&F University, Yangling 712100, China \\ †Juela Township Government of Cuona County, Cuona 856700, China \\ ¥College of Animal Science and Technology, Northwest A\&F University, Yangling 712100, China
}

\section{ABSTRACT}

Ketosis causes serious economic losses for the modern dairy industry because it is a highly prevalent metabolic disease among cows in high-producing herds during the transition period. Due to some striking similarities between diabetes in humans and ketosis in dairy cows, there is potential for the use of methylglyoxal (MGO) - commonly used in human diabetics - as a biomarker in dairy cattle. However, currently no data are available about the presence of MGO in the serum of dairy cattle or about the characteristics of its production or its potential contribution in the pathogenesis of ketosis. To determine the potential origin and pathway of formation of MGO, cows in different metabolic conditions [i.e., non-subclinically ketotic dairy cows in early lactation $(\mathrm{n}=7)$, subclinically ketotic dairy cows in early lactation $(\mathrm{n}=8)$, overconditioned dry cows $(\mathrm{BCS}>4.25, \mathrm{n}=6)$, and nonlactating heifers ( $\mathrm{n}$ $=6$ )] were selected. Serum MGO concentrations were determined and correlated with indicators of the glucose and lipid metabolism and with haptoglobin $(\mathrm{Hp})$ as an inflammatory marker. The serum MGO concentrations in subclinically ketotic cows $(712.60 \pm 278.77$ $\mathrm{nmol} / \mathrm{L}$ ) were significantly greater than in nonlactating heifers $(113.35 \pm 38.90 \mathrm{nmol} / \mathrm{L})$, overconditioned dry cows $(259.71 \pm 117.97 \mathrm{nmol} / \mathrm{L})$, and non-subclinically ketotic cows $(347.83 \pm 63.56 \mathrm{nmol} / \mathrm{L})$. In serum of lactating cows, concentrations of glucose and fructosamine were lower than in heifers and were negatively correlated with MGO concentrations. Even so, concentrations of metabolic and inflammatory markers such as dihydroxyacetone phosphate, nonesterified fatty acids, $\beta$-hydroxybutyrate, acetone, and $\mathrm{Hp}$ were remarkably higher in subclinically ketotic cows compared with non-

\footnotetext{
Received January 15, 2018.

Accepted May 15, 2018.

${ }^{1}$ Corresponding author: ardour@126.com or dongqiang@nwsuaf. edu.cn
}

lactating heifers; these metabolites were also positively correlated with MGO. In human diabetics elevated MGO concentrations are stated to originate from both hyperglycemia and the enhanced lipid metabolism, whereas higher MGO concentrations in subclinically ketotic cows were not associated with hyperglycemia. Therefore, our data suggest MGO in dairy cows to be a metabolite produced from the metabolization of acetone within the lipid metabolization pathway and from the metabolization of dihydroxyacetone phosphate. Furthermore, the highly positive correlation between MGO and $\mathrm{Hp}$ suggests that this reactive compound might be involved in the proinflammatory state of subclinical ketosis in dairy cows. However, more research is needed to determine the potential use of MGO as a biomarker for metabolic failure in dairy cows.

Key words: methylglyoxal, subclinical ketosis, dairy cow, glycolipid pathway

\section{INTRODUCTION}

Subclinical ketosis is an important metabolic disorder in high-producing dairy cows, affecting 30 to $40 \%$ of animals, especially during early lactation (Ametaj et al., 2016). According to some authors, there are 2 distinct types of ketosis: type I, characterized by hypoglycemia-hypoinsulinemia, and type II, characterized by hyperglycemia-hyperinsulinemia (Holtenius and Holtenius, 1996). The latter type shows striking similarities with type II diabetes in humans because, like type II diabetes occurs in obese humans, it mainly occurs in overconditioned cows (Holtenius and Holtenius, 1996).

Negative energy balance (NEB) in early-lactating cows is characterized by a failure of hepatic gluconeogenesis to supply adequate glucose (GLU) for maintenance and lactation. An inadequate or poor adaptive response to NEB can lead to ketosis (Herdt, 2000). High concentrations of nonesterified fatty acids (NEFA) and low concentrations of GLU are furthermore accepted 
as major indicators of this NEB (Abuelo et al., 2014). Massive fat mobilization from different adipose depots drives NEFA into the liver via the blood circulation and leads to NEFA oxidation through fatty acid $\beta$-oxidation in hepatic mitochondria to produce energy (Drackley, 1999). When the oxidative capacity of the liver is exceeded due to an overload of NEFA, the excessive NEFA will transform into acetone (AC), acetoacetate, and BHB (ketosis) or be stored as triglycerides (TG) in hepatocytes (fatty liver; Bezerra et al., 2014).

In humans, methylglyoxal (MGO) - a relatively new biomarker for type II diabetes - is currently more and more in use (Ogawa et al., 2010; Eberhardt et al., 2012; Matafome et al., 2013). Methylglyoxal is formed enzymatically from the triose phosphate intermediates [glyceraldehyde 3-phosphate (GAP) and dihydroxyacetone phosphate (DHAP)] produced during glycolysis or from the metabolization of ketone bodies or threonine in the lipid metabolism (Phillips and Thornalley, 1993; Richard, 1993; Thornalley, 1996). Prolonged hyperglycemia $(125 \mathrm{mg} / \mathrm{dL})$ in diabetics will result in an increase of MGO because hyperglycemia provokes an increased glycolysis (Sheader et al., 2001; Shamsaldeen et al., 2016). Production via the lipid metabolism occurs during metabolization of ketobodies, finally leading to the production of $\mathrm{AC}$ that metabolizes into acetol and subsequently MGO, a reactive carbonyl and dicarbonyl substance (Casazza et al., 1984; Bondoc et al., 1999). Moreover, MGO has been associated with inflammation because MGO-induced oxidative and carbonyl stress can lead to an increase in advanced glycation end products and inflammatory events (Vulesevic et al., 2016).

So far, to the best of our knowledge, no data are available concerning the MGO serum concentration in cattle. Due to the abovementioned striking similarities between diabetes type II and ketosis type II and to the seriously stressed lipid metabolism in periparturient dairy cows, it would be interesting to know whether this potentially harmful metabolite is also present in the blood of dairy cows. Furthermore, DHAP and GAP can be produced by glycerol through the gluconeogenic pathway in cattle (Goff and Horst, 2001), resulting in another potential pathway leading to the production of MGO.

The goal of the present research was to explore whether and how MGO is produced within the glycolipid metabolism in dairy cows. To obtain the first insights about the possible origin of this molecule in cattle, we included healthy, nonlactating heifers and lactating cows as well as subclinically ketotic cows. Furthermore, to evaluate the potential association of this reactive substance with subacute inflammation, we tested the association of this molecule with haptoglobin
$(\mathbf{H p})$, a well-known subacute inflammation marker in transition cows.

\section{MATERIALS AND METHODS}

The study was carried out in strict accordance with the recommendations mentioned in Guide for the Care and Use of Laboratory Animals (National Research Council, 2011). All animal experimental procedures were approved by the Animal Care Commission of the College of Veterinary Medicine, Northwest A\&F University (Yangling, China). Every effort was made to minimize animal pain, suffering, and distress and to reduce the number of animals used.

\section{Animals}

The present study took place from June 2015 to May 2016 in Shaanxi Huayin Dairy farm located at N 34 $35^{\prime}$, E $109^{\circ} 55^{\prime}$. Cows $(n=27)$ were randomly selected from a 2,000-cow Holstein dairy herd with an average annual milk yield of $9,800 \mathrm{~kg}$. Included cows were divided into 4 groups: 6 nonlactating heifers of 15 mo of age, 6 overconditioned dry cows $($ BCS $>4.25$; Edmonson et al., 1989), 7 non-subclinically ketotic cows (2 wk in milk, BHB $<0.6 \mathrm{mmol} / \mathrm{L}, \mathrm{NEFA}<0.4 \mathrm{mmol} / \mathrm{L}$ ), and 8 recently calved cows that were subclinically ketotic $(2$ wk in milk, $1.2 \mathrm{mmol} / \mathrm{L} \leq \mathrm{BHB} \leq 3.0 \mathrm{mmol} / \mathrm{L}$; Duffield, 2000; Oetzel, 2004; Rutherford et al., 2016). Cows were fed TMR and had free access to water. The nutrient composition of the diets is presented in Table 1. The diets were formulated using the China Professional Manager Consultancy-Dairy software (version 3.1.05) from Cornell University (Ithaca, NY), University of Pennsylvania (Philadelphia), Miner Institute (Chazy, NY), and Lanzhou Precision Animal Husbandry Technology Co. Ltd. (Lanzhou, Gansu, China).

\section{Blood Collection and Determination of Metabolites}

Blood samples were taken during multiple herd visits when individual animals were at the requested period in lactation (DIM) and were collected from the jugular vein into plain vacuum tubes (Becton Dickinson, Franklin Lakes, NJ) in the morning before the cows had access to fresh feed. In total, $10 \mathrm{~mL}$ of blood was gathered, kept on ice, and transported to the laboratory. Blood samples were centrifuged at $1,500 \times g$ at $4^{\circ} \mathrm{C}$ for $10 \mathrm{~min}$. The serum was transferred into sterile microtubes (Corning Inc., Corning, NY) and preserved at $-80^{\circ} \mathrm{C}$ until analysis. Serum concentrations of BHB $(\mathrm{mmol} / \mathrm{L})$, NEFA $(\mathrm{mmol} / \mathrm{L})$, aspartate amino transferase $(\mathrm{U} / \mathrm{L})$, total bilirubin (TBIL; $\mu \mathrm{mol} / \mathrm{L}$ ), TG $(\mathrm{mmol} / \mathrm{L})$, and GLU $(\mathrm{mmol} / \mathrm{L})$ were colorimetrically 
Table 1. Nutritional parameters of the cow $\operatorname{diets}^{1}$

\begin{tabular}{lccc}
\hline Item & Heifers & $\begin{array}{c}\text { Overconditioned } \\
\text { dry cows }\end{array}$ & Lactating cows \\
\hline DM, \% & 53.64 & 42.41 & 53.9 \\
Nutrients, \% of DM & & & 6.42 \\
Crude ash & 6.85 & 11.78 & 13.87 \\
CP & 11.14 & 3.47 & 3.45 \\
Ether extract & 2.87 & 34.23 & 32.8 \\
NDF & 44.8 & 21.18 & 20.24 \\
ADF & 29.37 & $2.49^{2}$ & $1.69^{3}$ \\
Energy, Mcal/kg of DM & $2.2^{2}$ & & \\
\hline
\end{tabular}

${ }^{1}$ Heifers $(\mathrm{n}=6)$ were nonlactating and 15 mo of age. Overconditioned dry cows $(\mathrm{n}=6)$ had a BCS $>4.25$. Lactating cows $(\mathrm{n}=15)$ comprised non-subclinically ketotic $(\mathrm{BHB}<0.6 \mathrm{mmol} / \mathrm{L}$, nonesterified fatty acids $<0.4 \mathrm{mmol} / \mathrm{L})$ and subclinically ketotic $(1.2 \mathrm{mmol} / \mathrm{L} \leq \mathrm{BHB} \leq 3.0 \mathrm{mmol} / \mathrm{L})$ cows that were 2 wk in milk.

${ }^{2}$ Represents metabolic energy.

${ }^{3}$ Represents lactation net energy.

measured using the Beckman Coulter AU 5800 automatic biochemical analyzer (Beckman Coulter Inc., Brea, CA). Serum fructosamine (FA) concentrations were quantified using a specific kit based on the reduction of nitrotetrazolium blue (Nanjing Jiancheng Bioengineering Institute, Nanjing, China; Johnson et al., 1983).

\section{Detection and Determination of MGO in Serum}

Serum MGO was determined by HPLC-MS/MS (LC-20 AD, Shimadzu Corporation, Kyoto, Japan; API 2000 LC/MS/MS, SCIEX AB, Singapore). The method was previously published by Scheijen and Schalkwijk (2014). Briefly, serum $(250 \mu \mathrm{L})$ was mixed with $750 \mu \mathrm{L}$ of $o$-phenylenediamine $(10 \mathrm{mg}$ of $o$-phenylenediamine in $10 \mathrm{~mL}$ of $1.6 \mathrm{~mol} / \mathrm{L}$ perchloric acid) in an Eppendorf tube. The sample was stored on ice for $10 \mathrm{~min}$; it was then centrifuged at $21,000 \times g$ at $4^{\circ} \mathrm{C}$ for $20 \mathrm{~min}$, and the supernatant was harvested for further analysis. After an overnight $(20 \mathrm{~h})$ reaction at room temperature and shielded from light, $10 \mu \mathrm{L}$ was injected for HPLC-MS/ MS analysis. A WondaSil C18 reversed-phase column (Shimadzu Corp.; $150 \mathrm{~mm} \times 4.6 \mathrm{~mm}, 5 \mu \mathrm{m}$ ) was used. The mobile phase consisted of $5 \mathrm{mmol} / \mathrm{L}$ of formic acid solution (solvent A) and acetonitrile (solvent B). The flow velocity was $0.5 \mathrm{~mL} / \mathrm{min}$. The standard curves were made using the external standard 2-methylquinoxaline according to its peak area by plotting the concentration of standard quinoxaline derivative (nmol/L). Retention times were analyzed and used to calculate the serum MGO concentration relative to the standards.

\section{Determination of DHAP in Serum}

Serum DHAP was measured in accordance with Michal (1984). Briefly, $0.2 \mathrm{~mL}$ of serum was added to a 1 -mL perchloric acid solution $(0.6 \mathrm{~mol} / \mathrm{L})$. The sample was mixed and then centrifuged at $1,500 \times g$ at $4^{\circ} \mathrm{C}$ for $10 \mathrm{~min}$, and the supernatant was harvested for further analysis. The supernatant was mixed with a $0.2-\mathrm{mL}$ perchloric acid solution and $0.2 \mathrm{~mL}$ of double-distilled water and again centrifuged, keeping the supernatant for further analysis. Those 2 supernatant samples were blended together. The $\mathrm{pH}$ of the solution was adjusted to 3.5 using a $\mathrm{K}_{2} \mathrm{CO}_{3}$ solution, adjusting the final volume to $1.6 \mathrm{~mL}$ and getting the final deproteinized filtrate sample. We then added $0.3 \mathrm{~mL}$ of buffer (triethanolamine, $0.4 \mathrm{~mol} / \mathrm{L}, \mathrm{pH} 7.6$; EDTA, $40 \mathrm{mmol} / \mathrm{L}$ ), $0.3 \mathrm{~mL}$ of deproteinized filtrate, and $10 \mu \mathrm{L}$ of reduced $\beta-\mathrm{NADH}$ successively. The resulting sample was mixed, and initial absorbance (A1) at $339 \mathrm{~nm}$ was read 2 or more times every $3 \mathrm{~min}$. Ten microliters of glycerol3 -phosphate dehydrogenase $(40 \mathrm{kU} / \mathrm{L})$ was added to the mixture and further mixed. After the reaction (5-7 min), absorbance A2 at $339 \mathrm{~nm}$ was read several times every 3 min. Then, A1 and A2 were subsequently used in the following formula: $\mathrm{A} 1-\mathrm{A} 2=\Delta \mathrm{A}_{\mathrm{DHAP}}$. One microliter of $\mathrm{K}_{2} \mathrm{Cr}_{2} \mathrm{O}_{7}$ (1\%, wt/vol) was added to the empty tube to partially compensate for the absorbance. The formula of the concentration of serum DHAP was

$$
\begin{gathered}
\text { DHAP concentration }(\mathrm{mmol} / \mathrm{L})= \\
\Delta \mathrm{A} \times \text { dilution times } /(\varepsilon \times d),
\end{gathered}
$$

where $\varepsilon$ is the molar extinction coefficient (6.22) and $d$ is the thickness of the fluid.

\section{Determination of AC in Serum}

Serum AC was measured by GC (DK-3001A headspace sampler, Shimadzu GC-2014C; Shimadzu Corp.) as previously described (Wagner et al., 1974; O'Neal et al., 1996) using butanone as the internal standard. Briefly, $900 \mu \mathrm{L}$ of the sample and $100 \mu \mathrm{L}$ of internal 
standard substances (butanone, $1 \mathrm{mmol} / \mathrm{L}$ ) were added in the 10-mL headspace vial and sealed. The resulting sample was equilibrated for $10 \mathrm{~min}$ at $65^{\circ} \mathrm{C}$, after which $1 \mathrm{~mL}$ of gas was injected for GC analysis. The GC was fitted with an Agilent DB-ALC1 chromatographic column $(30 \mathrm{~m} \times 0.25 \mathrm{~mm} \times 0.25 \mu \mathrm{m}$; Agilent Technologies, Santa Clara, CA). The injection temperature was $150^{\circ} \mathrm{C}$, and all injections were made in the split mode (20:1). The column, detector, and transfer line temperatures were 40,250 , and $110^{\circ} \mathrm{C}$, respectively. The 8-point concentration gradients were prepared for AC $(1-2,000 \mu \mathrm{mol} / \mathrm{L})$. The standard curve was drawn according to the peak area ratio of the standard $\mathrm{AC}$, and $\mathrm{AC}$ concentration in the serum was calculated according to the standard curve.

\section{Determination of Hp in Serum}

The concentration of Hp was determined by means of the hemoglobin binding assay described by Makimura and Suzuki (1982), and standard serum was purified by inflammatory serum of mastitic cows according to the method described by Zhu (2002). Briefly, an aliquot of $0.1 \mathrm{~mL}$ of a diluted hemoglobin ${ }^{+}$solution was mixed with $0.02 \mathrm{~mL}$ of the serum sample. Then, $0.02 \mathrm{~mL}$ of the mixture was transferred to a tube containing $5 \mathrm{~mL}$ of an $o$-dianisidine reagent. The content was mixed and incubated in a water bath at $37^{\circ} \mathrm{C}$ for $45 \mathrm{~min}$, and then $0.05 \mathrm{~mL}$ of $200 \mathrm{mmol} / \mathrm{L} \mathrm{H}_{2} \mathrm{O}_{2}$ was added. The sample was mixed and allowed to stand at room temperature for $1 \mathrm{~h}$, after which the absorbance was read at $440 \mathrm{~nm}$. The formula of the concentration of serum Hp was
Hp concentration $(\mathrm{mg} / \mathrm{L})=$ standard serum $(\mathrm{mg} / \mathrm{L})$

$$
\times \mathrm{OD}_{\text {sample }} / \mathrm{OD}_{\text {standard, }}
$$

where OD = optical density.

\section{Statistical Analysis}

Statistical analyses were performed using SAS version 9.4 (SAS Institute Inc., Cary, NC). Descriptive statistics are expressed as mean \pm standard deviation unless otherwise indicated. Normality of the variables was checked using the Kolmogorov-Smirnov test. All variables were compared in an ANOVA model with group as the independent variable. Homoscedasticity was checked using Levene's test. When variances within groups differed significantly, variables were $\log 10$ transformed. Pairwise comparisons were made between groups using Tukey's honest significant difference test. Pearson correlation coefficients were calculated to demonstrate the relationship between NEFA or BHB and other relevant metabolites, between indicators of the GLU metabolism and other relevant metabolic parameters, and between MGO and other relevant metabolites and inflammatory markers. Significance was declared at $P<0.05$.

\section{RESULTS}

\section{Indicators of GLU Metabolism}

As shown in Table 2, serum GLU and FA concentrations were lowest in the subclinically ketotic cows,

Table 2. Serum glycolipid and inflammatory metabolites (mean \pm SD) in the 4 groups of cows ${ }^{1}$

\begin{tabular}{|c|c|c|c|c|}
\hline Item & Heifers & $\begin{array}{l}\text { Overconditioned } \\
\text { dry cows }\end{array}$ & $\begin{array}{c}\text { Non-subclinically } \\
\text { ketotic cows }\end{array}$ & $\begin{array}{l}\text { Subclinically } \\
\text { ketotic cows }\end{array}$ \\
\hline $\mathrm{BCS}$ & $4.00 \pm 0.16^{\mathrm{B}, \mathrm{a}}$ & $4.67 \pm 0.13^{\mathrm{A}, \mathrm{a}}$ & $3.43 \pm 0.31^{\mathrm{B}, \mathrm{b}}$ & $3.84 \pm 0.50^{\mathrm{B}, \mathrm{a}}$ \\
\hline Methylglyoxal, nmol/L & $113.35 \pm 38.90^{\mathrm{B}}$ & $259.71 \pm 117.97^{\mathrm{B}}$ & $347.83 \pm 63.56^{\mathrm{B}}$ & $712.60 \pm 278.77^{\mathrm{A}}$ \\
\hline Glucose, $\mathrm{mmol} / \mathrm{L}$ & $3.91 \pm 0.29^{\mathrm{A}}$ & $2.94 \pm 0.23^{\mathrm{B}}$ & $3.01 \pm 0.20^{\mathrm{B}}$ & $2.17 \pm 0.33^{\mathrm{C}}$ \\
\hline Dihydroxyacetone phosphate, $\mu \mathrm{mol} / \mathrm{L}$ & $37.03 \pm 9.15^{\mathrm{B}}$ & $33.45 \pm 9.19^{\mathrm{B}}$ & $74.87 \pm 44.72^{\mathrm{A}}$ & $91.58 \pm 24.49^{\mathrm{A}}$ \\
\hline Fructosamine, mmol/L & $2.26 \pm 0.19^{\mathrm{A}}$ & $1.95 \pm 0.13^{\mathrm{A}}$ & $1.93 \pm 0.12^{\mathrm{A}}$ & $1.39 \pm 0.36^{\mathrm{B}}$ \\
\hline Nonesterified fatty acids, $\mathrm{mmol} / \mathrm{L}$ & $0.06 \pm 0.02^{\mathrm{B}}$ & $0.26 \pm 0.16^{\mathrm{B}}$ & $0.20 \pm 0.08^{\mathrm{B}}$ & $1.04 \pm 0.50^{\mathrm{A}}$ \\
\hline $\mathrm{BHB}, \mathrm{mmol} / \mathrm{L}$ & $0.46 \pm 0.12^{\mathrm{B}}$ & $0.42 \pm 0.12^{\mathrm{B}}$ & $0.42 \pm 0.11^{\mathrm{B}}$ & $1.85 \pm 0.42^{\mathrm{A}}$ \\
\hline Aspartate amino transferase, $\mathrm{U} / \mathrm{L}$ & $57.52 \pm 6.64^{\mathrm{B}, \mathrm{c}}$ & $44.53 \pm 5.12^{\mathrm{B}, \mathrm{c}}$ & $82.43 \pm 6.37^{\mathrm{A}, \mathrm{b}}$ & $105.84 \pm 23.01^{\mathrm{A}, \mathrm{a}}$ \\
\hline Acetone, $\mu \mathrm{mol} / \mathrm{L}$ & $-^{2}$ & $261.15 \pm 44.02^{\mathrm{B}}$ & $81.30 \pm 25.35^{\mathrm{B}}$ & $888.36 \pm 299.12^{\mathrm{A}}$ \\
\hline Total bilirubin, $\mu \mathrm{mol} / \mathrm{L}$ & $1.67 \pm 0.73^{\mathrm{B}}$ & $8.05 \pm 2.00^{\mathrm{A}}$ & $1.73 \pm 0.61^{\mathrm{B}}$ & $7.80 \pm 4.38^{\mathrm{A}}$ \\
\hline Triglyceride, $\mathrm{mmol} / \mathrm{L}$ & $0.21 \pm 0.08^{\mathrm{A}}$ & $0.25 \pm 0.04^{\mathrm{A}}$ & $0.10 \pm 0.02^{\mathrm{B}}$ & $0.10 \pm 0.03^{\mathrm{B}}$ \\
\hline Haptoglobin, mg/L & $17.21 \pm 4.92^{\mathrm{b}}$ & $16.50 \pm 6.07^{\mathrm{b}}$ & $48.55 \pm 65.15^{\mathrm{b}}$ & $209.32 \pm 182.49^{\mathrm{a}}$ \\
\hline
\end{tabular}

$\overline{\mathrm{A}, \mathrm{B}}$ Means within a row with different uppercase superscripts differ significantly using ANOVA testing $(P<0.01)$.

${ }^{\mathrm{a}-\mathrm{c}}$ Means within a row with different lowercase superscripts differ significantly using ANOVA testing $(P<0.05)$.

${ }^{1}$ Heifers $(\mathrm{n}=6)$ were nonlactating and 15 mo of age. Overconditioned dry cows $(\mathrm{n}=6)$ had a BCS $>4.25$. Lactating cows $(\mathrm{n}=15)$ comprised non-subclinically ketotic $(\mathrm{BHB}<0.6 \mathrm{mmol} / \mathrm{L}$, nonesterified fatty acids $<0.4 \mathrm{mmol} / \mathrm{L} ; \mathrm{n}=7)$ and subclinically ketotic $(1.2 \mathrm{mmol} / \mathrm{L} \leq \mathrm{BHB} \leq$ $3.0 \mathrm{mmol} / \mathrm{L} ; \mathrm{n}=8$ ) cows that were $2 \mathrm{wk}$ in milk.

${ }^{2}$ The concentration of acetone in the serum of heifers was lower than the detection level $(1 \mu \mathrm{mol} / \mathrm{L})$. 

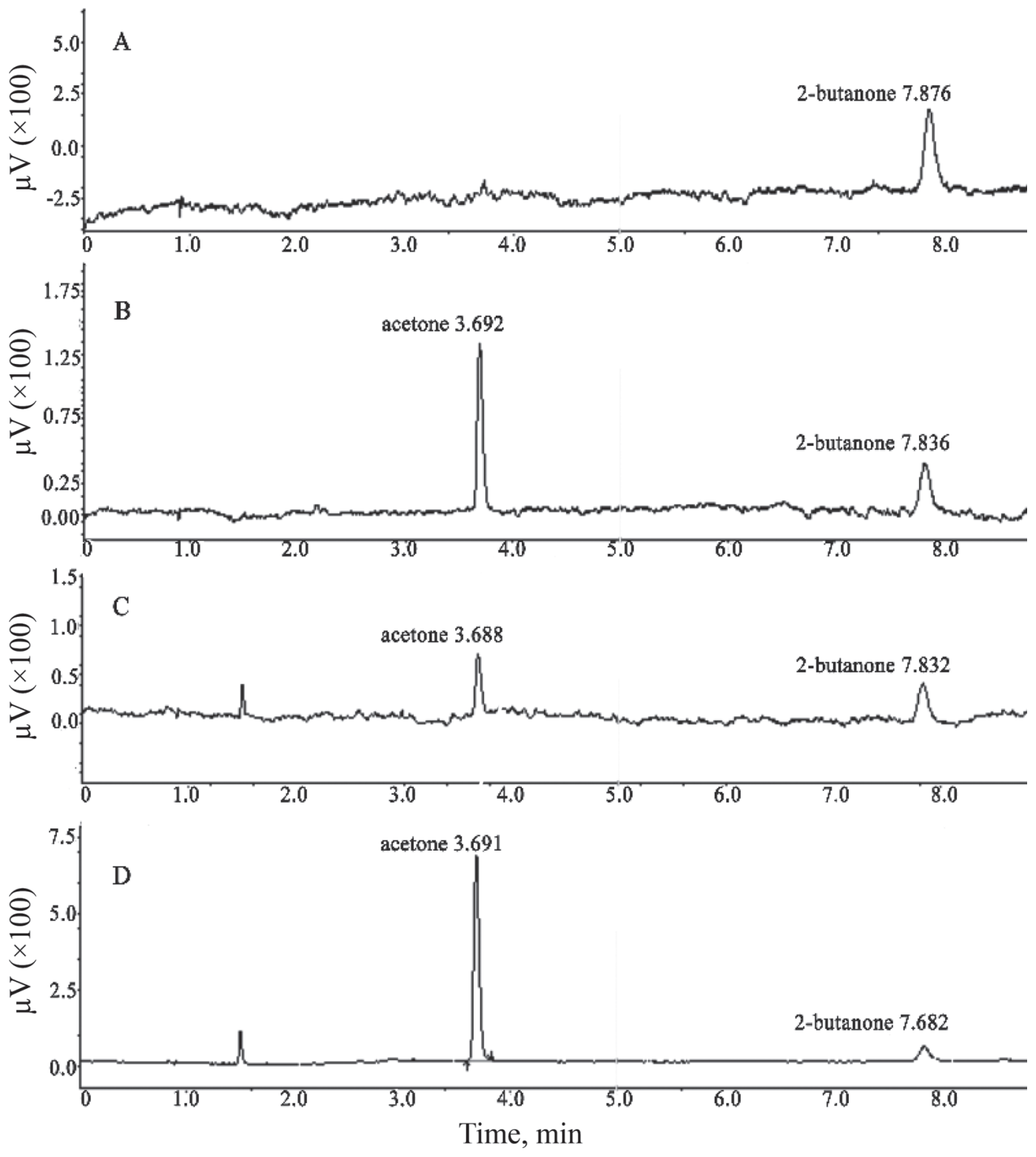

Figure 1. The GC analysis of serum acetone in dairy cows: (A) heifers, (B) overconditioned dry cows, (C) non-subclinically ketotic cows, and (D) subclinically ketotic cows.

whereas they were highest in the heifers $(P<0.01)$. Serum DHAP was higher in the non-subclinically ketotic and subclinically ketotic cows $(P<0.01)$ than in the heifers.

\section{Indicators of Lipid Metabolism}

Figure 1 illustrates the chromatograph of AC. As shown in Table 2, compared with the heifers and nonsubclinically ketotic cows, the concentrations of NEFA,
BHB, AC, aspartate amino transferase, and TBIL were significantly higher in the subclinically ketotic cows $(P<0.01)$. Serum TG in the subclinically ketotic and non-subclinically ketotic cows was significantly lower than in the heifers and overconditioned cows $(P<$ 0.01). Compared with heifers and non-subclinically ketotic cows, the concentrations of serum TBIL were significantly higher in the subclinically ketotic cows $(P$ $<0.01)$. Serum TBIL in the overconditioned cows was higher than that in the heifers $(P<0.01)$. 


\section{Serum MGO Concentrations}

As shown in Figure 2, the retention time of serum MGO in HPLC was 14.65 min. Serum MGO in the subclinically ketotic cows was higher than in the nonsubclinically ketotic cows $(P<0.01)$. Furthermore, the serum MGO showed a numerically ascending trend when going from heifers and overconditioned dry cows toward non-subclinically ketotic cows; however, there was no significant difference between the groups (Table 2).

\section{Serum Hp Concentrations}

As shown in Table 2, subclinically ketotic cows had the highest $\mathrm{Hp}$ concentrations $(P<0.05)$. The lowest Hp concentration was detected in the overconditioned dry cows and the heifers, although there was no significant difference between those 2 groups $(P=1.00)$.

\section{Correlation Analyses}

Results of the correlation analyses are shown in Tables 3,4 , and 5. Special attention has been paid to the correlation between MGO and the other metabolites and this correlation in all cows and in the lactating cows separately. Interesting findings are the significantly negative correlations between MGO and GLU and FA and the significantly positive correlation between MGO and AC, NEFA, BHB, and Hp. Data shown in Table 4 confirm the correlation between metabolites of the GLU metabolism.

\section{DISCUSSION}

To our knowledge, this is the first study to report on the peripheral concentration and metabolic pathway of MGO in the dairy cow. In addition, other less frequently determined but potentially important metabolites such as DHAP, FA, and AC were determined in serum samples of nonlactating heifers, overconditioned dry cows, non-subclinically ketotic cows, and subclinically ketotic cows in the early postpartum period using an innovative quantitative chromatographic methodology.

Compared with other species in which peripheral MGO concentrations have been quantified such as the human, the concentrations we found in serum of nonlactating heifers were relatively low (113.35 \pm 38.90 $\mathrm{nmol} / \mathrm{L}$ vs. $147 \mathrm{nmol} / \mathrm{L}$ in the healthy human at an average age of $48.7 \mathrm{yr}$; Lu et al., 2011). The plasma MGO concentrations of healthy females at an average age of $44.5 \mathrm{yr}$ have been described to be 1.38 -fold that of healthy males at an average age of $45.6 \mathrm{yr}$ (Ogasawara et al., 2016), and the plasma concentration of diabetics has been described as 2- to 4-fold that of healthy individuals (McLellan et al., 1994). In the human, MGO is stated to mainly originate from both glycolysis and the stressed lipid metabolism (Kalapos, 2013; Shamsaldeen et al., 2016). In diabetics, both the glycolysis pathway and lipid metabolization are significantly enhanced; therefore, concentrations of MGO have been shown to increase significantly $(190 \mathrm{nmol} / \mathrm{L})$, eventually contributing to some pathologic features of diabetes (Dmitriev and Dugin, 2007). In the present study, the highest MGO concentrations were found in subclinically ketotic cows in the immediate postpartum period. Results of our study show that MGO concentrations in subclinically ketotic cows are about 3.5 times higher than those in diabetics, which suggests MGO to be potentially harmful as they have been shown to be toxic in diabetics (Beisswenger, 2014). Furthermore, the MGO concentrations were higher in non-subclinically ketotic cows early postpartum and overconditioned dry cows compared with nonlactating heifers. Because the nonlactating heifers were at an age of 15 mo and hence not at the end of pregnancy or lactating, they did not experience a significant GLU drain to the uterus or udder (Abeni et al., 2000). Consequently, these younger animals had higher GLU, which was accompanied by lower MGO. Overall, data furthermore showed a significantly negative correlation between GLU and MGO. Both observations may suggest that MGO in the dairy cow mainly originates from the lipid metabolism and not via glycolysis. Furthermore, higher MGO concentrations were detected in the lactating cows in early lactation, which further confirms our reasoning because it is well known that lipid metabolization in immediate postpartum cows is heavily stressed due to NEB (Abdelhameed, 2016). The latter is furthermore evidenced by the significantly positive correlation between MGO and both NEFA and BHB, as found in the present study.

The concentrations of DHAP and AC were quantified for the first time in the serum of dairy cows. As could be expected, the results of our study show that $\mathrm{AC}$ concentrations in sera of subclinically ketotic cows were significantly higher than those in non-subclinically ketotic cows and nonlactating heifers. The in vivo (in mice) and in vitro research has demonstrated that $\mathrm{AC}$ can be transformed into acetol by CYP2E1 and then into MGO (Bondoc et al., 1999), which substantiates the highly positive correlation found between $\mathrm{AC}$ and MGO in the present study.

The lipid metabolization and its pathway to finally produce MGO has so far not been studied intensively in cows, and the knowledge as represented in Figure 3 is mainly based on what is known in humans. In the present study, serum DHAP was negatively correlated 

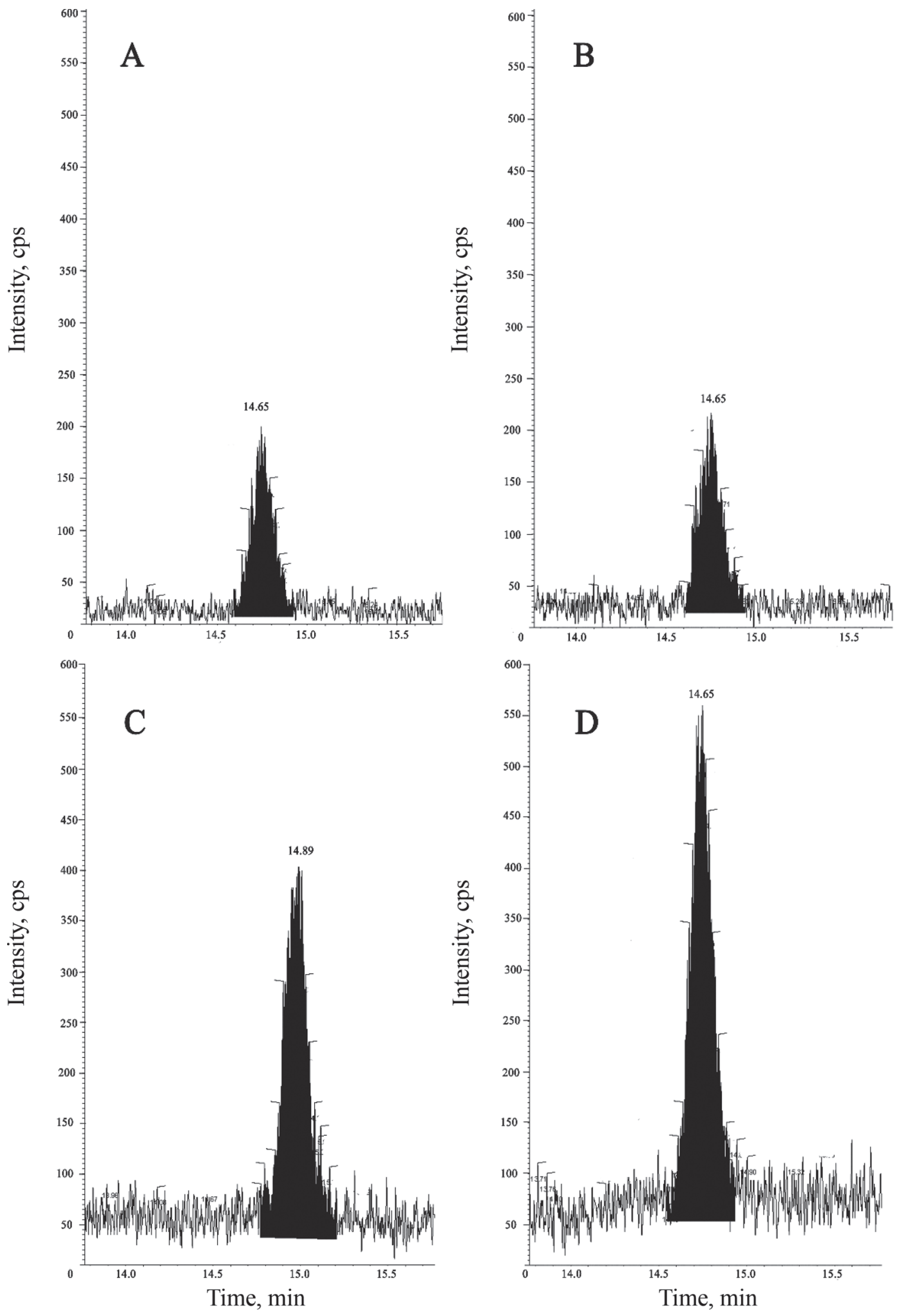

Figure 2. The HPLC-MS analysis of serum methylglyoxal in dairy cows: (A) heifers, (B) overconditioned dry cows, (C) non-subclinically ketotic cows, and (D) subclinically ketotic cows. 
with GLU, whereas it showed a positive correlation with both NEFA and BHB. These findings suggest that serum DHAP originates from glycerol, an intermediate of the lipid metabolism (Figure 3), and not from the GLU metabolism. However, it has been demonstrated in humans and in rats that under normal physiological conditions, glycerol can be enzymatically metabolized to DHAP and GAP by $\alpha$-glycerophosphate dehydrogenase. With the help of MGO synthase, DHAP can be transformed into MGO (Lee and Park, 2017); this might be another pathway by which MGO is produced, especially in dairy cows in early lactation because their peripheral glycerol level is enhanced due to tissue mobilization during NEB (Bell, 1995). Research has furthermore shown that MGO synthase can be found in the liver of goats (Ray and Ray, 1981), suggesting that MGO synthase is able to transform DHAP into MGO in this organ. The pathway described here is rather hypothetical because it is based on what is known in human medicine. Further research based on a very specific study design is warranted to confirm this proposed pathway.

Fructosamine is formed by the nonenzymatic reaction of GLU or its metabolites with the $\alpha$ - and $\varepsilon$ - amino groups of proteins to form intermediate compounds called Amadori products (Thornalley et al., 1999). This is the early glycation process, after which FA further forms advanced glycation end products (Thornalley, 1999; Singh et al., 2001). Thus, the concentration of FA in serum is generally considered to reflect the degree of glycaemic control (Kalaria et al., 2016). In dairy cows, FA reflects the average blood GLU concentration for the past 2 to $3 \mathrm{wk}$, and it potentially is a more sensitive indicator of the energy and carbohydrate status than blood GLU (Ropstad, 1987). Hence, the lower serum FA concentrations in the subclinically ketotic cows compared with non-subclinically ketotic cows in the present study confirm the hypoglycemic state of these cows. In humans, MGO is commonly considered a marker of glycation that goes along with increased serum FA (Adeshara and Tupe, 2016), whereas in rats

Table 3. Correlation between serum nonesterified fatty acids (NEFA) or BHB and relevant metabolites in all cows $(\mathrm{n}=27)$

\begin{tabular}{lcc}
\hline Item & $\begin{array}{c}\mathrm{NEFA}, \\
\mathrm{mmol} / \mathrm{L}\end{array}$ & $\begin{array}{c}\mathrm{BHB}, \\
\mathrm{mmol} / \mathrm{L}\end{array}$ \\
\hline Glucose, mmol/L & $-0.617^{* *}$ & $-0.678^{* *}$ \\
Dihydroxyacetone phosphate, $\mu \mathrm{mol} / \mathrm{L}$ & $0.440^{*}$ & $0.425^{*}$ \\
Fructosamine, mmol/L & $-0.866^{* *}$ & $-0.716^{* *}$ \\
Acetone, $\mu$ mol/L & $0.662^{* *}$ & $0.865^{* *}$ \\
Aspartate amino transferase, $\mathrm{U} / \mathrm{L}$ & $0.455^{*}$ & $0.678^{* *}$ \\
Total bilirubin, $\mu \mathrm{mol} / \mathrm{L}$ & $0.741^{* *}$ & $0.438^{*}$ \\
Triglyceride, $\mathrm{mmol} / \mathrm{L}$ & -0.256 & $-0.410^{*}$ \\
\hline
\end{tabular}

${ }^{*} P<0.05,{ }^{* *} P<0.01 ;$ Pearson test. 
Table 5. Correlation between serum methylglyoxal (nmol/L) and other metabolites and inflammatory markers in the serum of all cows $(\mathrm{n}=27)$ and lactating cows ${ }^{1}(\mathrm{n}=15)$

\begin{tabular}{lcc}
\hline Item & All cows & Lactating cows \\
\hline Glucose, mmol/L & $-0.768^{* *}$ & $-0.635^{*}$ \\
Dihydroxyacetone phosphate, $\mu \mathrm{mol} / \mathrm{L}$ & $0.463^{*}$ & 0.074 \\
Fructosamine, mmol/L & $-0.696^{* *}$ & $-0.548^{*}$ \\
Acetone, $\mu \mathrm{mol} / \mathrm{L}$ & $0.689^{* *}$ & $0.672^{* *}$ \\
Nonesterified fatty acids, mmol/L & $0.701^{* *}$ & $0.584^{*}$ \\
BHB, mmol/L & $0.787^{* *}$ & $0.729^{* *}$ \\
Aspartate amino transferase, U/L & $0.593^{* *}$ & 0.252 \\
Total bilirubin, $\mu \mathrm{mol} / \mathrm{L}$ & $0.396^{*}$ & 0.500 \\
Triglyceride, mmol/L & $-0.468^{*}$ & 0.054 \\
Haptoglobin, mg/L & $0.640^{* *}$ & $0.541^{*}$ \\
\hline
\end{tabular}

${ }^{1}$ The lactating cows include subclinically ketotic cows and non-subclinically ketotic cows 2 wk in milk.

${ }^{*} P<0.05,{ }^{* *} P<0.01$; Pearson test.

MGO has been shown to be correlated with milk FA (Francisco et al., 2018).

In the present study, Hp, a distinct marker of inflammation, was positively correlated with MGO. In humans, it has been reported that MGO is able to induce inflammation through the formation of advanced glyca- tion end products (Vlassara et al., 2002). Moreover, previous in vitro studies from our group as well as from others have shown that MGO is able to induce oxidative stress and inflammation directly or through the formation of advanced glycation end products (Yang et al., 2011; Seo et al., 2014; Zhang et al., 2017). Hence,

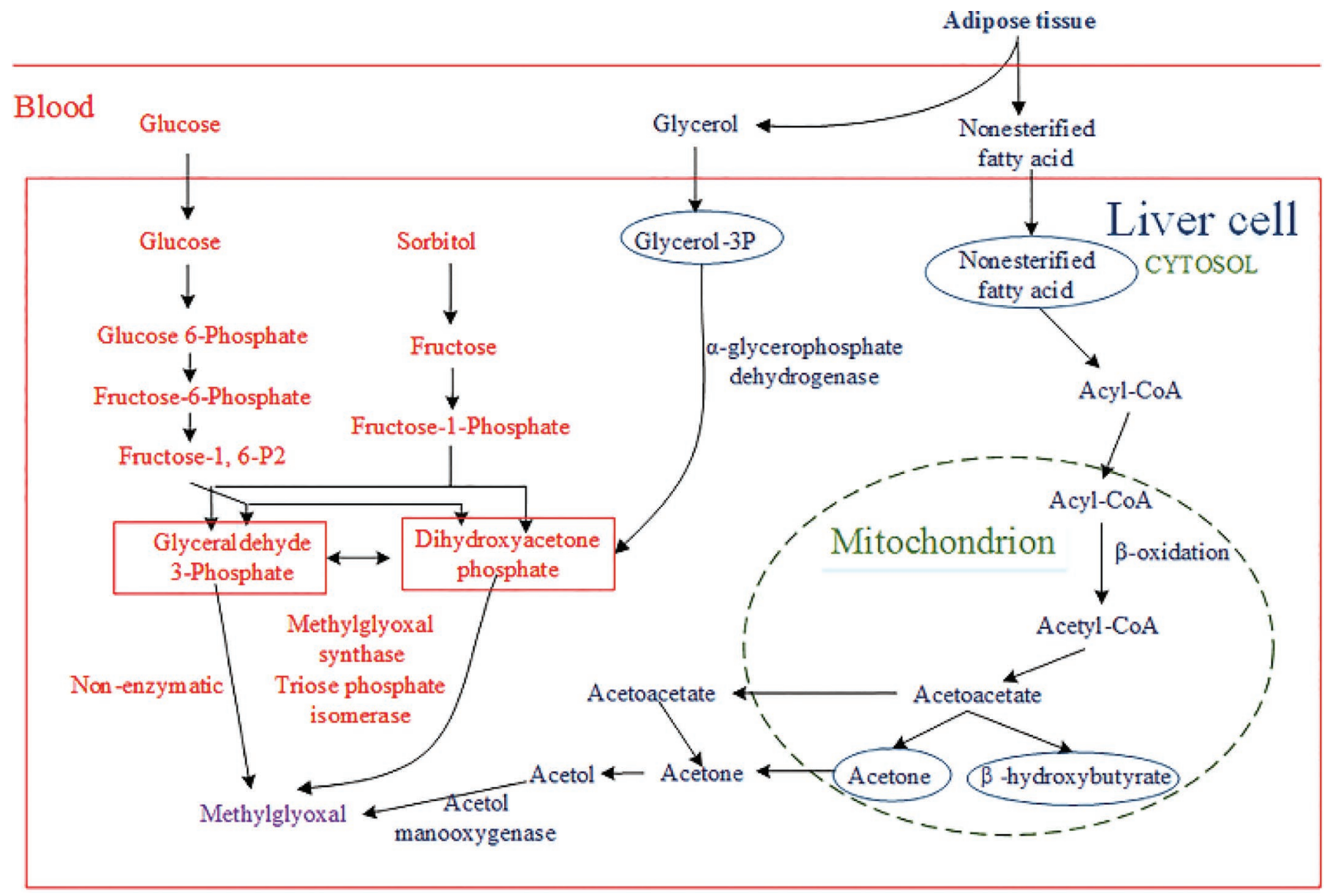

Figure 3. Hypothetical endogenous methylglyoxal formation pathway in dairy cows. Color version available online. 
there are reasons to believe that in the present study MGO might have contributed to the inflammatory state that was evidenced by the higher Hp concentrations in the subclinically ketotic cows. However, more research including a higher number of cows is needed to explore whether MGO indeed contributes to the inflammatory state of recently calved dairy cows.

\section{CONCLUSIONS}

Results of the present study show for the first time that MGO is present and can be determined in the blood of dairy cows. The concentration of MGO is higher in cows in early lactation, especially in subclinically ketotic animals. The higher peripheral MGO concentrations in subclinically ketotic cows were not associated with a condition of hyperglycemia as they are in human diabetics. Moreover, our data suggest MGO to be a metabolite produced from the metabolization of $\mathrm{AC}$ in the lipid metabolization pathway and from the metabolization of DHAP produced during gluconeogenesis via glycerol. Our data furthermore illustrate a distinct positive correlation between MGO and $\mathrm{Hp}$, suggesting that this metabolite might contribute to the inflammatory state metabolically stressed cows experience during the periparturient period. However, more research is needed to confirm this finding.

\section{ACKNOWLEDGMENTS}

This study was funded by the National Natural Science Foundation of China (Beijing; 31001090/C1808), Science and Technology Project in Yangling Demonstration Zone (Xi'an, Shaanxi, China; 2016NY-20), and Shaanxi Provincial Science and Technology Project (Yangling, Shaanxi, China; 2015NY164), the People's Republic of China.

\section{REFERENCES}

Abdelhameed, A. A. 2016. Evaluation of negative energy and mineral balance in periparturient Holstein-Friesian cattle. PhD Thesis. Purdue University, West Lafayette, IN.

Abeni, F., L. Calamari, L. Stefanini, and G. Pirlo. 2000. Effects of daily gain in pre- and postpubertal replacement dairy heifers on body condition score, body size, metabolic profile, and future milk production. J. Dairy Sci. 83:1468-1478.

Abuelo, A., J. Hernandez, J. Benedito, and C. Castillo. 2014. A comparative study of the metabolic profile, insulin sensitivity and inflammatory response between organically and conventionally managed dairy cattle during the periparturient period. Animal $8: 1516-1525$

Adeshara, K., and R. Tupe. 2016. Antiglycation and cell protective actions of metformin and glipizide in erythrocytes and monocytes. Mol. Biol. Rep. 43:195-205.

Ametaj, B., G. Zhang, E. Dervishi, S. Dunn, R. Mandal, and D. Wishart. 2016. DI/LC-MS/MS-based metabolomics identifies early predictive serum biomarkers for ketosis in dairy cows. J. Anim. Sci. 94(Suppl. 5):72. (Abstr.)

Beisswenger, P. J. 2014. Methylglyoxal in diabetes: Link to treatment, glycaemic control and biomarkers of complications. Biochem. Soc. Trans. 42:450-456.

Bell, A. W. 1995. Regulation of organic nutrient metabolism during transition from late pregnancy to early lactation. J. Anim. Sci 73:2804-2819.

Bezerra, L. R., C. B. de Oliveira Neto, M. J. de Araújo, R. L. Edvan, W. D. C. de Oliveira, and F. B. Pereira. 2014. Major metabolic diseases affecting cows in transition period. Int. J. Biol. 6:85-94.

Bondoc, F. Y., Z. Bao, W.-Y. Hu, F. J. Gonzalez, Y. Wang, C. S. Yang, and J.-Y. Hong. 1999. Acetone catabolism by cytochrome P450 2E1: Studies with CYP2E1-null mice. Biochem. Pharmacol. 58:461-463.

Casazza, J. P., M. Felver, and R. Veech. 1984. The metabolism of acetone in rat. J. Biol. Chem. 259:231-236.

Dmitriev, L. F., and S. F. Dugin. 2007. Aldehydes and disturbance of carbohydrate metabolism: Some consequences and possible approaches to its normalization. Arch. Physiol. Biochem. 113:87-95.

Drackley, J. K. 1999. Biology of dairy cows during the transition period: The final frontier? J. Dairy Sci. 82:2259-2273.

Duffield, T. 2000. Subclinical ketosis in lactating dairy cattle. Vet. Clin. North Am. Food Anim. Pract. 16:231-253.

Eberhardt, M. J., M. R. Filipovic, A. Leffler, J. de la Roche, K. Kistner, M. J. Fischer, T. Fleming, K. Zimmermann, I. Ivanovic-Burmazovic, and P. P. Nawroth. 2012. Methylglyoxal activates nociceptors through transient receptor potential channel A1 (TRPA1): A possible mechanism of metabolic neuropathies. J. Biol. Chem. 287:28291-28306

Edmonson, A., I. Lean, L. Weaver, T. Farver, and G. Webster. 1989 A body condition scoring chart for Holstein dairy cows. J. Dairy Sci. $72: 68-78$.

Francisco, F. A., L. F. Barella, S. da Silva Silveira, L. P. Jacinto Saavedra, K. V. Prates, V. S. Alves, C. C. da Silva Franco, R. A. Miranda, T. A. Ribeiro, L. P. Tófolo, A. Malta, E. Vieira, K. PalmaRigo, A. Pavanello, I. P. Martins, V. M. Moreira, J. C. de Oliveira, P. C. de Freitas Mathias, and R. M. Gomes. 2018. Methylglyoxal treatment in lactating mothers leads to type 2 diabetes phenotype in male rat offspring at adulthood. Eur. J. Nutr. 57:477-486.

Goff, J., and R. Horst. 2001. Oral glycerol as an aid in the treatment of ketosis/fatty liver complex. J. Dairy Sci. 84(Suppl. 1):153. (Abstr.)

Herdt, T. H. 2000. Ruminant adaptation to negative energy balance: Influences on the etiology of ketosis and fatty liver. Vet. Clin. North Am. Food Anim. Pract. 16:215-230.

Holtenius, P., and K. Holtenius. 1996. New aspects of ketone bodies in energy metabolism of dairy cows: A review. Zentralbl Veterinarmed A 43:579-587.

Johnson, R. N., P. A. Metcalf, and J. R. Baker. 1983. Fructosamine: A new approach to the estimation of serum glycosylprotein. An index of diabetic control. Int. J. Clin. Chem. 127:87-95.

Kalapos, M. P. 2013. Where does plasma methylglyoxal originate from? Diabetes Res. Clin. Pract. 99:260-271.

Kalaria, T. R., H. B. Sirajwala, and M. G. Gohel. 2016. Serum fructosamine, serum glycated albumin and serum glycated $\beta$-lipoprotein in type 2 diabetes mellitus patients with and without microvascular complications. J. Diabetes Metab. Disord. 15:53.

Lee, C., and C. Park. 2017. Bacterial responses to glyoxal and methylglyoxal: Reactive electrophilic species. Int. J. Mol. Sci. 18:169.

Lu, J., E. Randell, Y. Han, K. Adeli, J. Krahn, and Q. H. Meng. 2011. Increased plasma methylglyoxal level, inflammation, and vascular endothelial dysfunction in diabetic nephropathy. Clin. Biochem. 44:307-311.

Makimura, S., and N. Suzuki. 1982. Quantitative determination of bovine serum haptoglobin and its elevation in some inflammatory diseases. Jap. J. Vet. Sci. 44:15-21.

Matafome, P., C. Sena, and R. Seiça. 2013. Methylglyoxal, obesity, and diabetes. Endocrine 43:472-484.

McLellan, A. C., P. J. Thornalley, J. Benn, and P. H. Sonksen. 1994. Glyoxalase system in clinical diabetes mellitus and correlation with diabetic complications. Clin. Sci. 87:21-29. 
Michal, G. 1984. D-Fructose 1, 6-bisphosphate, dihydroxyacetone phosphate and D-glyceraldehyde 3-phosphate. Methods Enzymatic Anal. 6:342-350.

National Research Council. 2011. Guide for the Care and Use of Laboratory Animals. 8th ed. National Academies Press, Washington, DC.

O'Neal, C. L., C. E. Wolf, B. Levine, G. Kunsman, and A. Poklis. 1996. Gas chromatographic procedures for determination of ethanol in postmortem blood using t-butanol and methyl ethyl ketone as internal standards. Forensic Sci. Int. 83:31-38.

Oetzel, G. R. 2004. Monitoring and testing dairy herds for metabolic disease. Vet. Clin. Food Anim. Pract. 20:651-674.

Ogasawara, Y., R. Tanaka, S. Koike, Y. Horiuchi, M. Miyashita, and M. Arai. 2016. Determination of methylglyoxal in human blood plasma using fluorescence high performance liquid chromatography after derivatization with 1, 2-diamino-4, 5-methylenedioxybenzene. J. Chromatogr. B Analyt. Technol. Biomed. Life Sci. 1029-1030:102-105.

Ogawa, S., K. Nakayama, M. Nakayama, T. Mori, M. Matsushima, M. Okamura, M. Senda, K. Nako, T. Miyata, and S. Ito. 2010 Methylglyoxal is a predictor in type 2 diabetic patients of intimamedia thickening and elevation of blood pressure. Hypertension $56: 471-476$.

Phillips, S. A., and P. J. Thornalley. 1993. The formation of methylglyoxal from triose phosphates. Eur. J. Biochem. 212:101-105.

Ray, S., and M. Ray. 1981. Isolation of methylglyoxal synthase from goat liver. J. Biol. Chem. 256:6230-6233.

Richard, J. P. 1993. Mechanism for the formation of methylglyoxal from triosephosphates. Biochem. Soc. Trans. 21:549-553.

Ropstad, E. 1987. Serum fructosamine levels in dairy cows related to metabolic status in early lactation. Acta Vet. Scand. 28:291-298.

Rutherford, A. J., G. Oikonomou, and R. F. Smith. 2016. The effect of subclinical ketosis on activity at estrus and reproductive performance in dairy cattle. J. Dairy Sci. 99:4808-4815.

Scheijen, J. L., and C. G. Schalkwijk. 2014. Quantification of glyoxal, methylglyoxal and 3-deoxyglucosone in blood and plasma by ultra performance liquid chromatography tandem mass spectrometry: Evaluation of blood specimen. Clin. Chem. Lab. Med. 52:85-91.

Seo, K., S. H. Ki, and S. M. Shin. 2014. Methylglyoxal induces mitochondrial dysfunction and cell death in liver. Toxicol. Res. 30:193198.
Shamsaldeen, Y. A., L. S. Mackenzie, L. A. Lione, and C. D. Benham. 2016. Methylglyoxal, a metabolite increased in diabetes is associated with insulin resistance, vascular dysfunction and neuropathies. Curr. Drug Metab. 17:359-367.

Sheader, E. A., R. S. Benson, and L. Best. 2001. Cytotoxic action of methylglyoxal on insulin-secreting cells. Biochem. Pharmacol. 61:1381-1386.

Singh, R., A. Barden, T. Mori, and L. Beilin. 2001. Advanced glycation end-products: A review. Diabetologia 44:129-146.

Thornalley, P. 1999. The clinical significance of glycation. Clin. Lab. 45:263-273.

Thornalley, P. J. 1996. Pharmacology of methylglyoxal: Formation, modification of proteins and nucleic acids, and enzymatic detoxification - A role in pathogenesis and antiproliferative chemotherapy. Gen. Pharm. Vascular System 27:565-573.

Thornalley, P. J., A. Langborg, and H. S. Minhas. 1999. Formation of glyoxal, methylglyoxal and 3-deoxyglucosone in the glycation of proteins by glucose. Biochem. J. 344:109-116.

Vlassara, H., W. Cai, J. Crandall, T. Goldberg, R. Oberstein, V. Dardaine, M. Peppa, and E. J. Rayfield. 2002. Inflammatory mediators are induced by dietary glycotoxins, a major risk factor for diabetic angiopathy. Proc. Natl. Acad. Sci. USA 99:15596-15601.

Vulesevic, B., B. McNeill, F. Giacco, K. Maeda, N. J. Blackburn, M. Brownlee, R. W. Milne, and E. J. Suuronen. 2016. Methylglyoxalinduced endothelial cell loss and inflammation contribute to the development of diabetic cardiomyopathy. Diabetes 65:1699-1713.

Wagner, P. D., P. F. Naumann, and R. B. Laravuso. 1974. Simultaneous measurement of eight foreign gases in blood by gas chromatography. J. Appl. Physiol. 36:600-605.

Yang, K., D. Qiang, S. Delaney, R. Mehta, W. R. Bruce, and P. J. O'Brien. 2011. Differences in glyoxal and methylglyoxal metabolism determine cellular susceptibility to protein carbonylation and cytotoxicity. Chem. Biol. Interact. 191:322-329.

Zhang, T., Y. Mu, M. Yang, A. Al Maruf, P. Li, C. Li, S. Dai, J. Lu, and Q. Dong. 2017. (+)-Catechin prevents methylglyoxal-induced mitochondrial dysfunction and apoptosis in EA.hy926 cells. Arch. Physiol. Biochem. 123:121-127.

Zhu, J. 2002. Prification, analysis, and basal level of serum haptoglobin in cattle. MS Thesis. National Chung-Hsing University, Taiwan. 